\title{
Effects of cervical excisional procedures for cervical intraepithelial neoplasia on pregnancy and birth: A literature review
}

Rebecca Hay ${ }^{A, B}$ PG Dip, BHSC, BA, RM • Jean Patterson ${ }^{c}$ PhD, MA, BM, RM

${ }^{\mathrm{A}}$ Corresponding Author: rebecca@ osbornehay.co.nz

${ }^{\mathrm{B}}$ Liggins Institute, The University of Auckland; Warkworth Birthing Centre; self-employed midwife

${ }^{\mathrm{C}}$ Otago Polytechnic, Dunedin

\begin{abstract}
Background: Anecdotal evidence suggests midwives recognise that pregnancy and birth may be affected by cervical scarring caused by excisional procedures in the treatment of cervical intraepithelial neoplasia (CIN2 and 3). Affected women seeking information about the effect on their pregnancy and labour must rely on the knowledge of maternity care providers or take guidance from consumer publications. A literature review was undertaken with the objective of exploring pregnancy and birth outcomes following cervical excisional procedures.
\end{abstract}

Method: CINAHL, ProQuest, Pubmed, Google Scholar and Cochrane databases were searched for full text, peer-reviewed articles discussing either original research or systematic reviews, published from 2001-2016. Inclusion criteria were applied and comparative analysis was used to identify and compare outcomes.

Findings: Seventeen articles were included for review. Fifteen articles discuss the relationship of cervical excisional procedures to an increased incidence of preterm birth. Other outcomes include the increased incidence of preterm, pre-labour rupture of membranes, or consideration of associated low birthweight related to the method or depth of excision. No articles were found which considered the provision of intrapartum care to women with a history of cervical excision procedures.

Conclusion: Current research regarding the effect of cervical excision procedure history on pregnancy and birth is largely limited to quantifying the incidence of preterm birth and preterm, pre-labour rupture of membranes, or in discussing the impact of the method and depth of excision. Research to identify, describe, or best clinically manage the experience of birthing at term with cervical scarring appears to be absent. Further research is needed to extend midwifery knowledge regarding the provision of care during pregnancy and labour to affected women at term.

Keywords: cervical intraepithelial neoplasia (CIN), large loop excision of the transformation zone (LLETZ), loop electrosurgical excision procedure (LEEP), cold knife cone biopsy or excision (CKC), labour, birth

\section{INTRODUCTION}

Cervical screening in New Zealand is offered to women aged 2069. Women with low grade squamous intraepithelial lesions or atypical squamous cells of undetermined significance are recalled on a 12-month basis and, if recurrence is seen, may be offered colposcopy and biopsy. Women with identified high grade abnormal squamous cell changes (CIN2) or severe changes/ carcinoma in situ (CIN3) are offered treatment by a cervical excision procedure.

Incidence and treatment of CIN2 and 3 peak at around 30 years of age (Arbyn et al., 2008), similar to the median age for women giving birth in New Zealand, and slightly higher than the median age of 28 for first births (Statistics New Zealand, 2012). Any potential threat, related to treatment of CIN2 or 3, which risks the prospect of a successful pregnancy and birth is highly relevant to women of reproductive age (Arbyn et al., 2008).

The most common cause of CIN2 and 3 is human papilloma virus (HPV; National Screening Unit, 2008), for which the New Zealand
Ministry of Health introduced immunisation in 2008 (The New Zealand HPV Project, 2016). In 2018 the earliest participants in the programme turn 30 years old (Ministry of Health, 2014); however, uptake of the vaccination programme in New Zealand is currently only $60 \%$ (Petousis-Harris, 2016), leaving many women of reproductive age unprotected from HPV virus and carrying an increased risk of developing subsequent CIN2 and 3. From 1 July, 2017, the treatment programme offered a broader vaccine, targeting nine strains of HPV, given in two doses to both females and males (PHARMAC, 2016). Further, the National Cervical Screening Programme included primary screening for the presence of HPV (National Screening Unit, 2016), with the aim of reducing the incidence of CIN2 and 3 over time. However, small numbers of affected women will remain, and it is important for midwives to understand how these surgeries may impact pregnancy and birth.

Cervical excision procedures for women with CIN2 or 3 lesions include ablative therapy (cauterisation of cervical tissue through heat, laser or chemicals), large loop excision of the transformation 
zone (LLETZ), also known as loop electro-excisional procedure (LEEP), cold knife cone biopsy or excision (CKC), and sometimes hysterectomy if there are co-morbidities. Cryotherapy (extreme cold used to kill tumour cells) is not used in New Zealand but may be used in other countries (National Screening Unit, 2008).

$\mathrm{CKC}$ requires a general anaesthetic, and all ablative techniques destroy the tissue in situ and do not allow for histology. LLETZ has found favour since the early 1990s, as it enables the precise removal of affected tissue which can be sent for histology. It is usually an outpatient procedure, performed under local anaesthetic, and results in comparatively less post-procedural pain, bleeding and infection than other methods (Castanon et al., 2014; Kyrgiou et al., 2006; Sadler et al., 2004).

It has been proposed that removal of cervical tissue, which contains collagen and elastic fibres, leads to reduced mechanical integrity and support for the cervix (Sadler et al., 2004). An additional theory suggests that the removal of epithelial cells which secrete cervical mucus may reduce or alter local bacterial flora and thereby reduce immunological defences (Basama \& Angala, 2010; Sasieni et al., 2016).

The New Zealand Referral Guidelines require lead maternity carers to recommend obstetric referral where a woman has a history of either preterm birth or "cervical surgery, including cone biopsy, laser excision or LLETZ of the transformation zone" (Ministry of Health, 2012, p.24), unless the current pregnancy is subsequent to a successful vaginal birth post-surgery, or the depth of cone excised by LLETZ is less than $16 \mathrm{~mm}$ and histology is available (Ministry of Health, 2012).

The goal of this literature review was to locate available literature regarding pregnancy and birth outcomes following cervical excision procedures to treat $\mathrm{CIN} 2$ or 3 , and to focus on the relationship of cervical excision procedures to the risk of preterm birth. In New Zealand, the total rate of preterm birth (prior to 37 weeks gestation) is currently 7.4\% (Ministry of Health, 2015) and, internationally, it is estimated at $11.1 \%$ (Howson, Kinney,
\& Lawn, 2012), which has consequences for affected women, babies and families, and significant ongoing costs for health service provision and funding (Sasieni et al., 2016).

This review, therefore, reports predominantly on the available obstetric and epidemiological research published relating to the methods and depth of excisions, and to the outcomes of preterm birth and preterm pre-labour rupture of membranes (pPROM). Consideration of the relationship between cervical excisions and outcomes, such as neonatal mortality, low birthweight, caesarean section and fertility, are discussed as well as risk factors such as presence of vaginal infections and lifestyle factors.

\section{Objectives}

This review aimed to examine literature currently available on the impact of all forms of cervical excision procedures on pregnancy and childbirth, with the goals of:

- contributing to the body of knowledge midwives have to draw on in clinical practice,

- increasing the ability of women to make informed decisions about their care, and

- identifying any gaps in research.

\section{Search and selection criteria of literature}

An in-depth literature search of databases CINAHL, ProQuest, Pubmed, Cochrane Collaboration and Google Scholar was undertaken for peer-reviewed articles published between 2001 and 2016, using the search terms: "cervical intraepithelial neoplasia", "large loop excision of the transformation zone (LLETZ)" and "loop electrosurgical excision procedure (LEEP)", paired with "labour" and "birth" and with a number of different word combinations and truncations (Figure1). Forty-eight articles were identified, of which 31 were excluded due to duplication, lack of relevance to the topic, unavailability of the full text, not original research or a systematic review, not in English, or older than dates searched (Figure 1). A total of 17 published studies

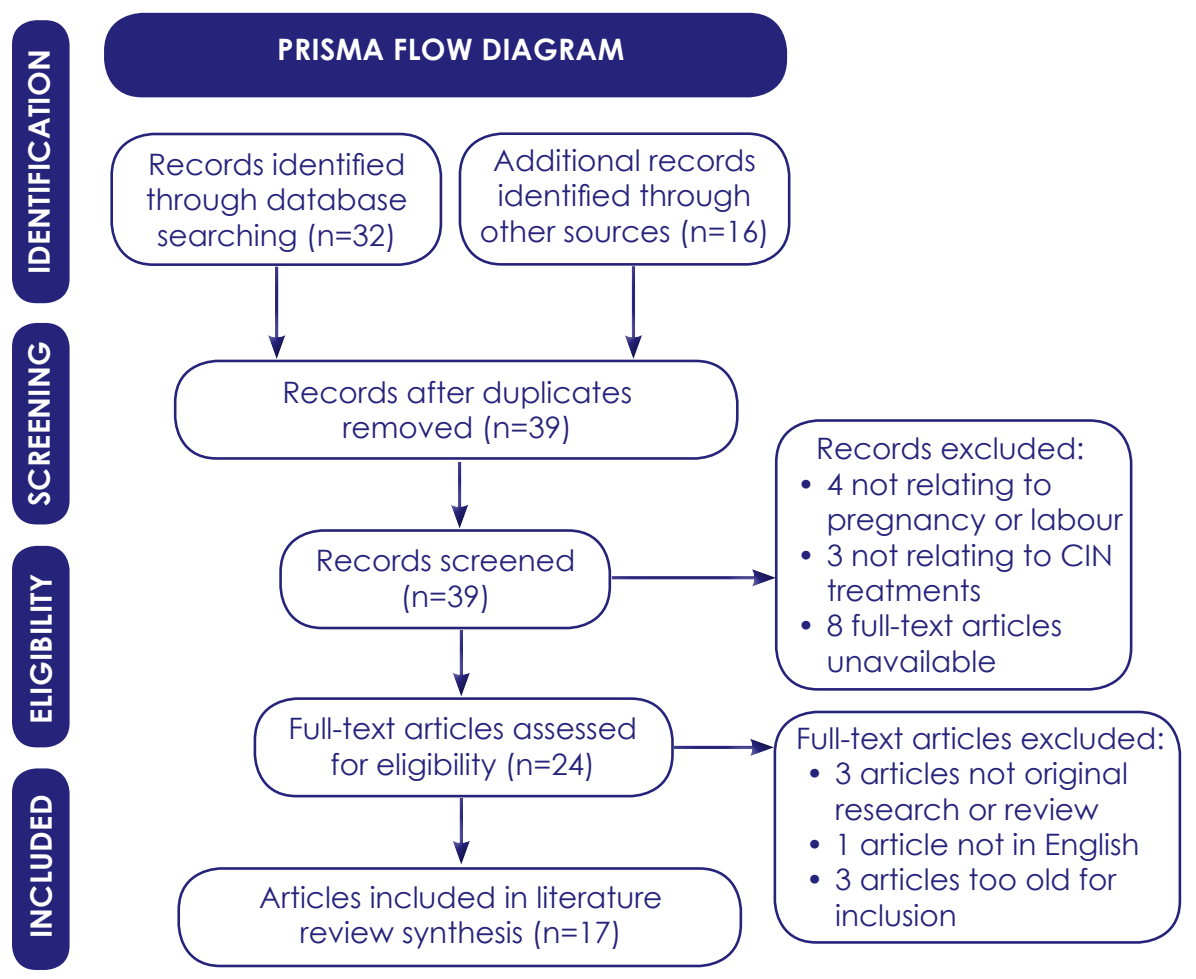

Figure 1. Literature search - PRISMA flow diagram 
were considered (Tables 1-4). Eight studies were from the United Kingdom (UK), four studies from the United States of America and one study each from New Zealand (NZ), Norway, Australia, Belgium and South Korea. Authors' disciplines were dominated by obstetrics, but included epidemiology and women's health. Employers were hospitals and universities, the one exception being GlaxoSmithKline's North American Vaccine Development. Several English studies were funded by the UK-based National Institute for Health Research, with authors collectively known as the PaCT study group (preterm delivery after treatment of the cervical transformation zone).

\section{RESULTS}

Sixteen of the included articles were quantitative studies or systematic reviews (Table 1). Fifteen articles discussed the relationship of cervical excisional procedures to the incidence of preterm birth, while one considered the outcome of caesarean delivery and one considered subsequent fertility. Other outcomes in the included articles were incidence of preterm birth and pPROM with respect to the depth or method of excision; and consideration of low birthweight/small for gestational age (SGA).

Themes discussed less frequently included cervical length in second trimester, benefit of cerclage (a strong suture inserted into and around the cervix), presence of vaginal infections, subsequent births, incidence of caesarean section delivery, neonatal mortality, and subsequent fertility. Three studies collected delivery details but did not discuss them in their publications, and three others commented negatively on women's "risky" behaviour, stating this contributes to the incidence of CIN2 and 3 and resultant treatment. From a midwifery perspective it would have been desirable to include any literature that discusses intrapartum care at term; however, most of the available literature focuses on identifying risks for preterm birth.

Results from this literature review are discussed firstly as they relate to aspects of preterm birth, and secondly as their impact on wider practice considerations. Statistical methods and reporting styles vary; for example, some studies report using relative risk or odds ratios calculations, while others provide results as percentages (Tables 2 and 3). Other studies adjust risks for variables such as age, ethnicity, socio-economic and lifestyle factors (Table 1). Results potentially reflect variations in the background risk of preterm labour in each population, or changes in outcomes or treatment methods over time. For example, Norwegian research outcomes over 36 years reflected progressive changes in the practice of providing CKC treatment from 1967 to 1980, with likely mixed treatments from 1980 to 1985 , laser treatment from 1985 to 1990 , and currently LLETZ since 1990 (Albrechtsen, Rasmussen, Thoresen, Irgens, \& Iversen, 2008).

\section{DISCUSSION}

\section{Concern about premature birth}

The major obstetric outcome of concern was increased risk of preterm birth following cervical excisional procedures, although risk differed between procedural methods used (Table 2) and depth of excisions (Table 3) and may be related to increased risk of pPROM (Table 4).

A New Zealand study of 1,078 women did not find any increased risk of preterm birth following cervical excision by any method (aRR 0.8, 95\% CI, 0.8-1.5), except where excisions exceeded a depth of $17 \mathrm{~mm}$ (Sadler et al., 2004). Simoens et al. (2012) found an increased incidence of preterm labour in $16.3 \%$ of 97 women with a history of undergoing the cervical excisional procedure, versus $8.1 \%$ of 194 unexposed women (OR 2.82, 95\% CI, 1.326.00). Similarly, a large Norwegian population-based cohort study of over 2 million births found preterm birth occurred in $17.2 \%$ of women birthing post excision, compared to $6.2 \%$ of women who had never had a cervical excisional treatment (Albrechtsen et al., 2008).

Initially, PaCT members Castanon et al. (2012) stated there was no significantly increased risk of preterm birth, either preceding or following cervical excisional procedures, due to quality improvements in treatments. However, in 2014 the PaCT group revised their position, stating that presence of CIN2 or 3, whether treated or untreated, increases the risk of preterm birth $(8.8 \%)$ compared to unaffected women (6.7\%; Castanon et al., 2014).

Studies differentiating outcomes between methods of cervical excision found wide disparities in outcome with regard to preterm birth. Most attention was given to the differences between LLETZ and CKC methods. In a systematic review and meta-analysis of 27 studies involving a total of 34,495 women, Kyrgiou et al. (2006) found LLETZ to be the safer option (RR 1.70, 95\% CI, 1.24-2.35) as opposed to CKC (RR 2.59, 95\% CI, 1.80-3.72) with regard to the risk of preterm birth. Australian systematic reviewers Bruinsma and Quinn (2011) supported this finding in their review of 30 studies, with LLETZ moderately increasing the risk of preterm birth (RR 1.85, 95\% CI, 1.59-2.15) versus the significantly increased risk following CKC (RR 3.41, 95\% CI, 2.38-4.88). Conner et al. (2014), published a review of 19 studies involving a total of over 1.4 million participants and found an increased incidence of preterm birth following LLETZ (RR 1.61, 95\% CI, 1.35-1.92), which contrasted with Arbyn et al. (2008) who conducted a review of research published over a long time frame (1960-2007) and found no increased risk to pregnancy from any method (including LLETZ) except from CKC (RR 2.87, 95\% CI, 1.72-4.51). It appears that, excepting the work of Arbyn et al., LLETZ is seen to moderately increase risk of preterm labour while $\mathrm{CKC}$ increases risk to significantly high levels.

The physical amount of cervical tissue excised was also a factor. Kyrgiou et al. (2006) found excision depth in excess of $10 \mathrm{~mm}$ was sufficient to increase rate of preterm birth (RR 2.6, 95\% CI, 1.35.3), and this finding was supported by Simoens et al. (2012), who found significantly increased risk of preterm birth with excision depth greater than $10 \mathrm{~mm}$ (aOR 4.55, 95\% CI, 1.32-15.65).

UK-based PaCT members made the clearest distinctions regarding depth of excision in their study of 11,471 women (Wuntakal, Castanon, Landy, \& Sasieni, 2015). Cervical excisions under $10 \mathrm{~mm}$, including punch biopsies, were not considered to increase the risk of preterm birth. Large cervical excisions over $15 \mathrm{~mm}$ (RR $2.04,95 \% \mathrm{CI}, 1.41-2.96)$ and very large excisions over $20 \mathrm{~mm}$ (RR 2.40, 95\% CI, 1.53-3.75) were found to bear a significant risk of preterm birth. As an example of the impact on women's and babies' health care services, the sole variable of a cervical excision greater than $10 \mathrm{~mm}$ was implicated as adding 840 preterm births to the annual total in England. Risk was not increased by repeated treatment itself, but rather by progressive increase in the depth of tissue removed (Castanon et al., 2014).

The small study by Sadler et al. (2004) found pPROM was increased in women who had laser conisation (RR 2.7, 95\% CI, 1.3-5.6) or LLETZ procedure (RR 1.9, 95\% CI, 1.0-3.8; Table 3). This study included 652 cases versus 426 controls but, interestingly, also found that incidence of pPROM was over three times higher in women with excision greater than $17 \mathrm{~mm}$ depth (RR 3.6, 95\% CI, 1.8-7.5) compared to the control group. Conversely, in their meta-analysis of 27 studies, Kyrgiou et al. (2006) found no increased risk of pPROM for women following laser conisation (RR 2.18, 95\% CI, 0.77-6.16) but did find that LLETZ increased risk of PPROM (RR 2.69, 95\% CI, 1.62-4.46). 
Table 1. Study design features and outcomes

Author(s) Methodology and procedure

$\begin{array}{ll}\text { Albrechtsen } & \text { Population-based cohort study: Included } \\ \text { et al., (2008) } & \text { all Norwegian births 1967-2003 }\end{array}$

Norway

Arbyn et al., Meta-analysis: 1960-2007 Pubmed-

(2008) UK Medline and Embase data search

\begin{tabular}{|c|c|}
\hline $\begin{array}{l}\text { Basama } \\
\text { \& Angala, } \\
\text { (2010) UK }\end{array}$ & $\begin{array}{l}\text { Postal survey of obstetric consultants } \\
\text { based in England }\end{array}$ \\
\hline $\begin{array}{l}\text { Bruinsma } \\
\text { \& Quinn, } \\
\text { (2011) } \\
\text { Australia }\end{array}$ & $\begin{array}{l}\text { Systematic review and meta-analysis } \\
\text { of } 30 \text { randomised controlled trials and } \\
\text { observational studies 1950-2009 }\end{array}$ \\
\hline $\begin{array}{l}\text { Castanon } \\
\text { et al., (2012) } \\
\text { UK }\end{array}$ & $\begin{array}{l}\text { Retrospective-prospective cohort study } \\
\text { of obstetric records 1998-2009 }\end{array}$ \\
\hline $\begin{array}{l}\text { Castanon } \\
\text { et al., (2014) } \\
\text { UK }\end{array}$ & $\begin{array}{l}\text { Case-control study nested in record } \\
\text { linkage cohort study. } 12 \text { English hospitals, } \\
\text { April } 1998 \text { to March } 2011 \text {, matching } \\
\text { histology records with obstetric records }\end{array}$ \\
\hline $\begin{array}{l}\text { Castanon } \\
\text { et al., (2015) } \\
\text { UK }\end{array}$ & Nested case-control study \\
\hline $\begin{array}{l}\text { Conner et } \\
\text { al., (2014) } \\
\text { USA }\end{array}$ & $\begin{array}{l}\text { Systematic review and meta-analysis of } \\
19 \text { observational studies of pregnancies } \\
\text { following LLETZ procedures }\end{array}$ \\
\hline $\begin{array}{l}\text { Frey et al., } \\
\text { (2013) USA }\end{array}$ & $\begin{array}{l}\text { Secondary analysis of a multicentre } \\
\text { retrospective analysis }\end{array}$ \\
\hline $\begin{array}{l}\text { Kyrgiou et } \\
\text { al., (2006) } \\
\text { UK }\end{array}$ & $\begin{array}{l}\text { Systematic review and meta-analysis of } \\
27 \text { controlled observational studies taken } \\
\text { from Medline and Embase data search } \\
1960-2004\end{array}$ \\
\hline
\end{tabular}

$\begin{array}{lll}\text { Naleway et } & \text { Retrospective matched cohort within a } & \text { Laser ablation, LLETZ, cold knife } \\ \text { al., (2015) } & \text { Kaiser Permanente hospital } & \text { cone biopsy, cryotherapy }\end{array}$

USA

\section{Medical procedures} included

Cold knife conisation until 1980 undocumented 1980-1985, laser treatments 1985-1990, LLETZ from 1990-1995

Excisional (cold knife conisation, LLETZ, and laser conisation): and ablative procedures (laser ablation, cryotherapy, and diathermy)

\section{Cold knife conisation, laser} conisation, LLETZ

\section{Excisional: CKC, laser}

conisation and LLETZ. Ablative:

cryotherapy, laser ablation (vaporisation)

History of cervical histology

compared to maternity event data

Excisional: LLETZ, laser excision/

ablation, cold knife cone biopsy

History of cervical colposcopy

compared to maternity event data

LLETZ only

\section{LLETZ only, and only in} relationship to caesarean section outcome

Cold knife conisation, laser conisation, LLETZ, laser ablation
Number of participants

15,108 women with history of cervical conisation; 2, 164,006 births to women with no history of conisation

One prospective and 19

$\begin{array}{ll}\text { One prospective and } 19 & \text { Preterm birth, excision } \\ \text { retrospective studies, included a } & \text { method, birth weight, }\end{array}$ total of 613,558 women

50 obstetric consultants

Participant numbers not stated

18,441 singleton births: 4,176 before cervical histology and 14,265 after cervical histology

11,471 women with histology by colposcopy. Comparing within that cohort: 768 preterm births with 830 term births

\section{2,798 births from 2,001 women} with history of colposcopy procedures

6,589 with history of LLETZ; $1,415,015$ without history of LLETZ

598 women with prior LLETZ, 588 with screening cytology (PAP smear) only, 552 with cervical (punch) biopsy

34,495 women

Primary outcomes considered

Preterm birth, excision perinatal mortality infections

Preterm birth, pPROM, cerclage excision, pPROM

Preterm birth

Preterm birth, depth of excision

Preterm birth, depth of excisions, 2 nd and

Preterm birth, pPROM

Caesarean section

Preterm birth, excision method, lifestyle factors lifestyle factors, vagina

Preterm birth, method of subsequent pregnancies method, excision depth pPROM, birthweight, perinatal mortality, labour duration, caesarean section, fertility

1,533 pregnancies in 13,767 women following diagnostic procedures; 570 pregnancies in 4,137 women following cervical treatment procedures; 7,436 pregnancies in 81,435 women with no history of procedures

\begin{tabular}{lll}
$\begin{array}{l}\text { Nam et al., } \\
\text { (2010) South } \\
\text { Korea }\end{array}$ & $\begin{array}{l}\text { Retrospective cohort study: review of } \\
\text { medical records at Yonsei University } \\
\text { Health System, Seoul. }\end{array}$ & $\begin{array}{l}\text { LLETZ and cold knife conisation } \\
\text { considered together }\end{array}$ \\
\hline $\begin{array}{l}\text { Sadler et al., } \\
\text { (2004) NZ }\end{array}$ & $\begin{array}{l}\text { Retrospective cohort study of women } \\
\text { presenting to National Women's Hospital } \\
\text { colposcopy clinic for the first time 1988- }\end{array}$ & $\begin{array}{l}\text { Laser conisation, laser ablation, } \\
\text { LLET. Excluded cryotherapy } \\
\text { and cold knife conisation due to } \\
\text { low frequency in the NZ context }\end{array}$
\end{tabular}
Reviews 65 cases of pregnancy following treatment over 13 years

Treated women $=652$; untreated women $=426$

Fertility, lifestyle factors

Preterm birth, cervical length, cerclage

Preterm birth, excision method, depth of excision, PPROM, lifestyle factors

Preterm birth, excision depth, cerclage, progesterone pessaries, 2nd and subsequent pregnancies, fertility epidemiologists

\begin{tabular}{ll}
\hline $\begin{array}{l}\text { Simoens et } \\
\text { al., (2012) } \\
\text { Belgium }\end{array}$ & $\begin{array}{l}\text { Multicentre cohort study using a } \\
\text { questionnaire and anonymised obstetric } \\
\text { files }\end{array}$ \\
\hline $\begin{array}{ll}\text { Stout et al., } \\
\text { (2015) USA }\end{array}$ & $\begin{array}{l}\text { Secondary analysis of multicentre } \\
\text { retrospective cohort study. Pregnancies } \\
\text { with/without history of LLETZ, comparing } \\
\text { presence or absence of vaginal infection }\end{array}$ \\
\hline Wuntakal et & $\begin{array}{l}\text { Retrospective case-control study linking } \\
\text { W. }\end{array}$
\end{tabular}

al., (2015) UK histology records with birthing records
Excisional: LLETZ, laser, cold knife conisation. Ablative: laser, electrocoagulation, cryotherapy $12.5 \%$

LLETZ only 1,727 women; 34.4\% had LLETZ

LLETZ, laser excision, cone biopsy by any method.
97 women with history of $\mathrm{CIN}$ treatment and 194 women with no history of CIN treatment

Preterm birth, excision depth, caesarean section, birth weight/SGA

Preterm labour, vaginal infection 
Table 2. Risk of preterm birth by excisional method

\begin{tabular}{|c|c|c|c|c|c|c|c|c|}
\hline \multirow[t]{2}{*}{ Author } & \multirow[t]{2}{*}{ Year } & \multicolumn{7}{|c|}{ Excisional method with risk ratio of preterm birth, $\mathrm{Cl} 95 \%$} \\
\hline & & Any & $\begin{array}{l}\text { Laser } \\
\text { conisation }\end{array}$ & LLETZ/LEEP & $\begin{array}{l}\text { Laser } \\
\text { ablation }\end{array}$ & CKC & Cryotherapy & $\begin{array}{l}\text { Punch } \\
\text { biopsy }\end{array}$ \\
\hline Arbyn et al. & 2008 & & $3.33(0.73-16.77)$ & $1.20(0.50-2.89)$ & $0.29(0.15-0.58)$ & $2.78(1.72-4.51)$ & $0.88(0.49-1.56)$ & \\
\hline $\begin{array}{l}\text { Bruinsma \& } \\
\text { Quinn }\end{array}$ & 2011 & & $3.58(1.93-6.61)$ & $\begin{array}{l}\text { OR } 1.85 \text { (1.59- } \\
2.15)\end{array}$ & & $\begin{array}{l}\text { RR } 3.41 \text { (2.38- } \\
4.88)\end{array}$ & & \\
\hline Castanon et al. & 2012 & $\begin{array}{l}1.32(1.13- \\
1.53)\end{array}$ & & & & & & $1.14(0.77-1.66)$ \\
\hline Castanon et al. & 2014 & & & & & & & $0.97(0.75-1.27)$ \\
\hline Castanon et al. & 2015 & & & & & & & $\begin{array}{l}\text { OR } 0.9 \text { (0.67- } \\
1.22)\end{array}$ \\
\hline Conner et al. & 2014 & & & $1.61(1.35-1.92)$ & & & & \\
\hline Kyrgiou et al. & 2006 & & & $1.70(1.24-2.35)$ & & $2.59(1.80-3.72)$ & & \\
\hline Sadler et al. & 2004 & $\begin{array}{l}\text { aRR 1.1 } \\
(0.8-1.5)\end{array}$ & aRR $1.3(0.8-2.2)$ & aRR $1.2(0.8-1.8)$ & aRR $0.8(0.5-1.2)$ & & & \\
\hline Simoens et al. & 2012 & $\begin{array}{l}2.82(1.32- \\
6.00)\end{array}$ & $2.52(0.62-10.25)$ & $\begin{array}{l}5.63(1.85- \\
17.15)\end{array}$ & & & & \\
\hline Stout et al. & 2015 & & & $1.4(1.1-1.8)$ & & & & \\
\hline
\end{tabular}

Table 3. Risk of preterm birth by depth of excision

\begin{tabular}{|c|c|c|c|c|c|}
\hline \multirow[t]{2}{*}{ Author } & \multirow[t]{2}{*}{ Year } & \multicolumn{4}{|l|}{ Depth of excision } \\
\hline & & $<10 \mathrm{~mm}$ & $10-14 \mathrm{~mm}$ or $>10 \mathrm{~mm}$ & $15-20 \mathrm{~mm}$ & $>20 \mathrm{~mm}$ \\
\hline Castanon et al. & 2014 & 1 (Reference) & RR 1.28 (0.98-1.68) & RR 2.04 (1.14-2.96) & RR 2.40 (1.53-3.75) \\
\hline Castanon et al. & 2015 & 1 (Reference) & OR 1.08 (0.80-1.45) & OR 1.95 (1.28-2.97) & OR 2.30 (1.35-3.92) \\
\hline Sadler et al. & 2004 & aRR $0.9(0.5-1.6)$ & aRR $1.1(0.6-1.9)^{*}$ & aRR $1.7(1.0-2.7)^{* *}$ & \\
\hline Simoens et al. & 2012 & aRR 2.77 (0.28-27.59) & aRR 4.55 (1.32-15.65) & & \\
\hline
\end{tabular}

* Sadler et al. used 10-16mm

** Sadler et al. used $>17$

\section{Table 4. Risk of pPROM by excisional method}

Author Year Excisional method with risk ratio of PPROM, Cl $95 \%$

\begin{tabular}{|c|c|c|c|c|c|}
\hline & \\
\hline & & Any & $\begin{array}{l}\text { Laser } \\
\text { conisation }\end{array}$ & $\begin{array}{l}\text { LLETZ/ } \\
\text { LEEP }\end{array}$ & $\begin{array}{l}\text { Excision } \\
>17 \mathrm{~mm}\end{array}$ \\
\hline $\begin{array}{l}\text { Bruinsma } \\
\text { \& Quinn }\end{array}$ & 2011 & $\begin{array}{l}3.40 \\
(1.63- \\
8.11)\end{array}$ & & & \\
\hline $\begin{array}{l}\text { Conner } \\
\text { et al. }\end{array}$ & 2014 & & & $\begin{array}{l}2.37 \\
(1.64- \\
3.44)\end{array}$ & \\
\hline $\begin{array}{l}\text { Kyrgiou } \\
\text { et al. }\end{array}$ & 2006 & & $\begin{array}{l}2.18(0.77- \\
6.16)\end{array}$ & $\begin{array}{l}2.69 \\
(1.62- \\
4.46)\end{array}$ & \\
\hline $\begin{array}{l}\text { Sadler et } \\
\text { al. }\end{array}$ & 2004 & & $2.7(1.3-5.6)$ & $\begin{array}{l}1.9(1.0- \\
3.8)\end{array}$ & $3.6(1.8-7.5)$ \\
\hline
\end{tabular}

A relationship between cervical excision and pPROM is supported, however, by two large systematic reviews and metaanalyses. Bruinsma and Quinn (2011) included studies employing all excisional techniques and found significantly increased risk (RR 3.40, 95\% CI, 1.63-8.11). Conner et al. (2014) considered LLETZ procedures alone, but also found increased risk of pPROM (RR 2.37, 95\% CI, 1.64-3.44). Of any excisional method, LLETZ procedures incurred the lowest risk of pPROM, and subsequent premature births, to women of reproductive age.

\section{Aspects relevant to clinical practice}

Other aspects discussed relevant to clinical practice include the effects of cervical surgery on subsequent pregnancies, the depth of excision and its relationship to cervical length, and other cervical treatments such as cerclage. Studies included in this literature review typically didn't comment specifically about parity in their results; however, in a nested, case-control PaCT study of 2,001 women over their 2,798 first and subsequent births, Castanon et al. (2015) identified that women with deep cervical excisions retained an increased risk of preterm birth during all pregnancies subsequent to treatment.

A 2015 London symposium, which included 50 oncologists, colposcopists, obstetricians and epidemiologists, was in agreement that subsequent pregnancies remained at risk of preterm birth, and specifically so for women with cervical excisions greater than $15 \mathrm{~mm}$ depth (Sasieni et al., 2016). The symposium group also viewed the cervical tissue remaining in situ following excision as important, and agreed that short cervical length (under $2.5 \mathrm{~cm}$ long) is accepted as predictive of preterm labour. The symposium group also agreed cerclage and/or progesterone pessaries could be used from the second trimester; however, the evidence for either, in preventing premature labour, is mixed.

In a British postal survey of 50 obstetricians, $72 \%$ responded that they would assess cervical length for pregnant women who had a history of cervical excisional procedures by ultrasound. Routine cervical cerclage would be offered by $62 \%$ obstetricians, with $48 \%$ offering it pre-conception (Basama \& Angala, 2010). One other study followed six participants over a 13-year time frame, three of whom experienced preterm labour and three of whom carried to term-a sample too small to achieve statistical significance (Nam, Kwon, Kim, \& Park, 2010). The included studies cannot be seen to be conclusive as to whether cerclage or progesterone pessaries are of benefit, and dedicated searches on these topics were not undertaken for this study. 
No studies discuss the duration of labour either at term or otherwise, even though the $\mathrm{PaCT}$ group state in three studies that they have collated delivery data (Castanon et al., 2012, 2014, 2015). This presents a lost opportunity to this literature review, although a retrospective analysis of the data could be possible. The closest statement about the duration of labour was by Kyrgiou et al., (2006), who found no link between LLETZ and precipitous birth (RR 1.26, 95\% CI, 0.75-2.11), and did not comment on other methods of excision.

\section{Other clinical implications}

Some studies alluded to clinical outcomes, such as the incidence of caesarean section, birth weight and perinatal mortality. The incidence of caesarean section in women treated for CIN2 or 3 was considered by three studies. By method of excision, Kyrgiou et al. (2006) found a history of CKC increased the incidence of caesarean section (RR 3.17, 95\% CI, 1.07-9.40), while LLETZ (RR 0.88, 95\% CI, 0.71-1.09), laser conisation (RR 1.16, 95\% $\mathrm{CI}, 0.64-2.09$ ) and laser ablation (RR 0.79 , 95\% CI, 0.49$1.25)$ did not increase the risk of caesarean section. Simoens et al. (2012) found no significant difference between incidence of caesarean section in treated women $(22.7 \%)$ compared to women not diagnosed or treated for CIN2 or $3(23.2 \%)$. A secondary analysis of a previous multicentre, retrospective analysis, which focused solely on the incidence of caesarean section following LLETZ compared to women with no history of colposcopy, found no difference in incidence of caesarean section (RR 1.06, 95\% CI, 0.79-1.41; Frey et al., 2013). In addition, labour arrest was not given as the reason for caesarean section delivery any more frequently following LLETZ than for controls, even in women with large excisions $(32.7 \%$ vs $31.3 \%, p=0.78)$. In a study of 1,738 women, incidence of caesarean section did not vary based on time elapsed between LLETZ and birth: at 12 months post LLETZ, incidence of caesarean section was $29.8 \%$ vs $31.8 \%$, $(\mathrm{p}=0.78)$, and at 24 months incidence of caesarean section was $31.1 \%$ vs $31.9 \%$, ( $\mathrm{p}=0.84$; Frey et al., 2013). Therefore, a history of LLETZ procedure is not found to be a reason to offer elective caesarean section.

The included studies generally did not separate low birth weight or small for gestational age babies from the incidence of preterm birth. For example, a Norwegian population-based cohort study, which included all births $(\mathrm{n}=2,164,006)$ from 1967 to 2003, grouped all babies with birthweight under $2500 \mathrm{~g}$ together with preterm births (Albrechtsen et al., 2008). Ultrasound was not used in Norway to estimate gestational age until 1998 and, until then, only the date of the last menstrual period was used, which could have increased dating errors. Definitions of low birth weight also varied between the included studies and ranged from $<2000 \mathrm{~g}$ to $<2500 \mathrm{~g}$.

One meta-analysis found that women with a history of CKC delivered babies with low birthweight (under 2500g) two-and-ahalf times more compared to controls (RR 2.53, 95\% CI, 1.195.36) and, following LLETZ procedures, nearly twice as often as controls (RR 1.82, 95\% CI, 1.09-3.06; Kyrgiou et al., 2006). In an analysis of a similar group of studies, Arbyn et al. (2008) likewise found $\mathrm{CKC}$ to be related to low birth weight, defined as under 2000g (RR 2.86, 95\% CI, 1.37-5.97), and that LLETZ did not contribute significantly to any morbidity or adverse outcomes.

It is not apparent from either of these findings whether there is any actual link between excisional history and fetal growth restriction. The only study to specifically measure risk of small for gestational age (under 10th centile for growth) found no relationship with cervical excision (OR 0.74, 95\% CI, 0.31-1.74; Simoens et al., 2012). This was a small study of 79 women and further research is needed.

Perinatal mortality was separated from preterm birth as an outcome in a systematic review and in a meta-analysis (Arbyn et al., 2008; Kyrgiou et al., 2006). Kyrgiou et al. (2006) found widely variable, inconclusive results by method: LLETZ (RR 3.40, 95\% CI, $0.62-$ 18.63); laser conisation, (RR 8.00, 95\% CI, 0.91-70.14); laser ablation (RR 0.67, 95\% CI, 0.11-3.96); and CKC (RR 1.89, 95\% CI, 0.77-4.65). However, Arbyn et al. (2008) found LLETZ to be the safer option, with no additional perinatal mortality attributed (pooled RR 1.17, 95\% CI, 0.74 to 1.87 ), while CKC led to significantly increased risk of perinatal mortality by nearly three times (RR 2.87, 95\% CI, 1.42-5.81).

No method of cervical excisional procedure had a negative effect on fertility or time to conceive (Kyrgiou et al., 2006). In a large, retrospective, matched cohort study involving 17,904 participants and 81,435 controls, Naleway et al. (2015) found the rate of pregnancy was actually increased following cervical excisional procedures, compared to women with no history of CIN2 or 3 or related treatment (RR 1.42, 95\% CI, 1.30-1.55).

\section{Potential impact of lifestyle factors}

It has been suggested that women treated for CIN2 or 3 are more sexually active than controls (Naleway et al., 2015). This view was supported by the New Zealand case-controlled study (Sadler et al., 2004), which included 1,078 women who had used the Auckland Hospital colposcopy clinic over a 12-year period, whether treated or not. The Sadler et al. study (2004) stated that, compared to the background population, all participants were predisposed to preterm labour due to certain "demographic, behavioural and sexual histories" (p.2105). Similarly, this association was also made by Arbyn et al. (2008), who commented that women treated for CIN2 or 3 lesions are "known to have demographic, behaviour and sexual characteristics that increase their risk of adverse obstetric outcomes" (p.8). The terms "sexual histories" and "sexual characteristics" were undefined by both sets of authors and appear to imply that women's sexuality is problematic.

These broad and unqualified statements are discriminatory given that, without vaccination, $80 \%$ of the population is infected with one or more strain of HPV and therefore at risk of developing CIN2 or 3 (Ministry of Health, 2014). However, women who are smokers are at increased risk, so there may be correlations between some lifestyle behaviours and the incidence of precancerous cervical neoplasia (Albrechtsen et al., 2008). Likewise, vaginal infections are established as contributing to risk of preterm labour. Arbyn et al. (2008) cited research which found that bacterial vaginosis has a higher incidence in women with CIN2 or 3 and is linked to pPROM, which subsequently increases the risk of preterm labour. However, Stout et al. (2015) refuted this claim and, after controlling for confounding factors, did not find an adjusted increased risk of preterm labour in women with a history of LLETZ procedure, in combination with bacterial vaginosis (aOR 0.9, 95\% CI, 0.7-1.2), chlamydia (aOR 0.9, 95\% CI, 0.71.2), gonorrhoea (aOR 1.3, 95\% CI, 0.9-1.9), trichomonas (aOR $1.1,95 \% \mathrm{CI}, 0.7-1.5)$, any vaginal infection (aOR $0.8,95 \% \mathrm{CI}$, 0.6-1.1), multiple vaginal infections (aOR 1.0, 95\% CI, 0.71.5 ) or pyelonephritis ( $\mathrm{OOR} 0.9,95 \% \mathrm{CI}, 0.4-1.7$ ). It is thought that excision affects the cervix mechanically and by reduction of immunological barriers via cervical mucus (Sasieni et al., 2016); therefore, presence of vaginal infections will likely continue to be perceived as causative until further research is available. 


\section{Relevance of the findings for midwifery care}

This review provides a hopeful picture for the future of women who require treatment for CIN2 or 3, largely due to improvements in treatment method. Lead maternity carer midwives and core midwives are well placed to share the findings of this literature review with treated women. It is recommended, on the basis of the literature accessed for this review in combination with the Referral Guidelines (Ministry of Health, 2012), that, for each pregnancy subsequent to precancerous neoplasia treatments, the following practice approaches be considered:

- When taking a health history at booking, ascertain the depth of excision of any cervical excisional procedure and obtain histology records if available.

- Recommend obstetric referral in first or early second trimester, particularly if the excision had a depth of $15 \mathrm{~mm}$ or more, or at any time a scan shows a shortened cervix.

- Include a request for cervical length measurement at the anatomy scan (18-20 weeks). Note: it is important to prepare women to anticipate that the scan method may use a transvaginal probe.

- Apprise women with a history of cervical excision procedure about the signs of labour initiation and pPROM and advise the need to seek urgent assessment if these signs present.

- Offer sexual health screening in early second trimester, when there are fewer contraindications to medications compared to the first trimester.

\section{Limitations of this review}

This literature review sought to include only original research or systematic analyses of original research. The exclusion of non-English language publications and grey literature, such as governmental publications or unpublished theses, may have prevented our identifying further articles for inclusion and could possibly have changed the results. We did not search any trial registers for trial protocols pertaining to effects of cervical excisional procedures for cervical intraepithelial neoplasia on pregnancy and birth which may have alerted the authors to possible protocol publications. While there would not have been any data available as yet, it could have alerted the authors and readers to future publications.

\section{Research gaps}

This systematic review identifies clear research gaps, including the lack of current literature which could contribute to the body of knowledge around the provision of intrapartum care at term to women with a history of cervical excisional procedures. Information regarding the pattern and duration of labour at term appears absent, as does literature considering the impact of common intrapartum interventions on affected women, such as induction of labour methods, for example, syntocinon infusion or artificial rupture of membranes, and the method of pain relief. Research into these aspects would benefit midwives in providing more appropriate intrapartum care for affected women.

Likewise, there appears to be no qualitative research, which could include consumer input to explore women's knowledge, understanding and experience of the impact of cervical excision procedures on their pregnancies and during labour, and any implications for the wellbeing of their babies. Midwives could contribute their experience and knowledge, for example, around how a scarred cervix may dilate during labour (particularly at term), findings on vaginal examination, beneficial actions and management in labour, information sharing with women, and antenatal and intrapartum decision points.

\section{CONCLUSION}

This literature review is consistent in revealing concerns about the relationship of cervical excisional procedure history to preterm birth. There is consensus that LLETZ procedures increase the risk of preterm labour to a moderate extent, while CKC is falling from favour in that it creates an unnecessary risk for women of reproductive age. Irrespective of method, when excisions are $>15 \mathrm{~mm}$, the risk of preterm birth is significantly increased and this risk does not change with subsequent pregnancies.

While the risk of pPROM is significantly elevated by all methods of cervical excision, it is unclear whether the additional presence of vaginal infections exacerbates the risk of both pPROM and preterm birth.

Cervical excision procedures have not been found to affect fertility or fetal growth, and LLETZ is not found to increase risk of caesarean section or neonatal mortality.

This review provides a hopeful picture for the future of women who require treatment for CIN2 or 3, largely due to improvements in treatment method. Gaps in the literature exist around caring for treated women birthing at term, and the duration and pattern of labour. Likewise, there appears to be no qualitative research to reflect the clinical experiences of midwives, or those experiences of women birthing following cervical intraepithelial neoplasia treatment. Such research would be of considerable interest to women and provide balanced evidence for practice for midwives and all maternity care providers.

\section{CONFLICT OF INTEREST STATEMENT}

The authors declare that there are no conflicts of interest.

\section{REFERENCES}

Albrechtsen, S., Rasmussen, S., Thoresen, S., Irgens, L.M., \& Iversen, O.E. (2008). Pregnancy outcome in women before and after cervical conisation: Population based cohort study. British Medical Journal, 337, a1343. http://www.bmj.com/content/337/bmj.a1343

Arbyn, M., Kyrgiou, M., Simoens, C., Raifu, A.O., Koliopoulos, G., Martin-Hirsch, P., ... Paraskevaidis, E. (2008). Perinatal mortality and other severe adverse pregnancy outcomes associated with treatment of cervical intraepithelial neoplasia: meta-analysis. British Medical Journal, 337, a1284. http://www.bmj.com/content/337/bmj.a1284

Basama, F.M.S., \& Angala, P. (2010). Survey: The management of pregnant women with a history of excisional treatment of the uterine cervix for cervical intra-epithelial neoplasia. Gynecological Surgery, 8(1), 79-84. https://link.springer.com/article/10.1007\%2Fs10397-010-0622z\#page-2

Bruinsma, F., \& Quinn, M. (2011). The risk of preterm birth following treatment for precancerous changes in the cervix: A systematic review and meta-analysis. BJOG: An International Journal of Obstetrics \& Gynaecology, 118 (9), 1031-1041. http://onlinelibrary.wiley.com/ doi/10.1111/j.1471-0528.2011.02944.x/full

Castanon, A., Brocklehurst, P., Evans, H., Peebles, D., Singh, N., Walker, P., ... Sasieni, P. (2012). Risk of preterm birth after treatment for cervical intraepithelial neoplasia among women attending colposcopy in England: Retrospective-prospective cohort study. British Medical Journal, 345, e5174. http://www.bmj.com/content/345/bmj.e5174 Castanon, A., Landy, R., Brocklehurst, P., Evans, H., Peebles, D., Singh, N., Walker, P., ... Sasieni, P. (2014). Risk of preterm delivery with increasing depth of excision for cervical intraepithelial neoplasia in England: Nested case-control study. British Medical Journal, 349, g6223. http://www.bmj.com/content/349/bmj.g6223

Castanon, A., Landy, R., Brocklehurst, P., Evans, H., Peebles, D., Singh, N., ... Sasieni, P. (2015). Is the increased risk of preterm birth following excision for cervical intraepithelial neoplasia restricted to the first birth post treatment? BJOG: An International Journal of Obstetrics and Gynaecology, 122, 1191-1199. http://onlinelibrary.wiley.com/ doi/10.1111/1471-0528.13398/full 
Conner, S.N., Frey, H.A., Cahill, A.G., Macones, G.A., Colditz, G.A., \& Tuuli, M.G. (2014). Loop electrosurgical excision procedure and risk of preterm birth: A systematic review and meta-analysis. Obstetrics and Gynecology, 123(4), 752-761. http://www.ncbi.nlm.nih.gov/pmc/articles/ PMC4113318/

Frey, H.A., Stout, M.J., Odibo, A.O., Stamilo, D M., Cahill, A.G., Roeh, K.A., \& Macones, G.A. (2013). Risk of cesarean delivery after loop electrosurgical excision procedure. Obstetrics and Gynecology; 121(1), 39-45. http://www.ncbi.nlm.nih.gov/pmc/articles/ PMC3547644/

Howson, C.P., Kinney, M.V., \& Lawn, J.E. (Eds.). (2012). Born too soon: The global action report on preterm birth. Geneva, Switzerland: March of Dimes, The Partnership of Maternal, Newborn and Child Health, Save the Children, World Health Organization. Retrieved from http://www.who.int/pmnch/media/news/2012/preterm_birth_report/en/ index $1 . h t m l$

Kyrgiou, M., Koliopoulos, G., Martin-Hirsch, P., Arbyn, M., Prendiville, W., \& Paraskevaidis, E. (2006). Obstetric outcomes after conservative treatment for intraepithelial or early invasive cervical lesions: Systematic review and meta-analysis. The Lancet, 367(9509), 489-498.

Ministry of Health. (2012). Guidelines for consultation with obstetric and related medical services (Referral Guidelines). Wellington: Ministry of Health. Retrieved from http://www.health.govt.nz/system/files/ documents/publications/referral-glines-jan12.pdf

Ministry of Health. (2014). History of the HPV immunisation programme. Retrieved from http://www.health.govt.nz/our-work/ preventative-health-wellness/immunisation/hpv-immunisationprogramme/history-hpv-immunisation-programme

Ministry of Health. (2015). Report on maternity 2014. Wellington: Ministry of Health. Retrieved from http://www.health.govt.nz/ publication/report-maternity-2014

Moher, D., Liberati, A., Tetzlaff, J., \& Altman, D.G. (2009). The PRISMA Group: Preferred Reporting Items for Systematic Reviews and Meta-Analyses: The PRISMA Statement. PLoS Medicine, 6(7), e1000097. https://doi.org/10.1371/journal.pmed.1000097

Naleway, A.L., Weinmann, S., Krishnarajah, G., Arondekar, B., Fernandez, J., Swamy, G., \& Myers, E. (2015). Pregnancy after treatment for cervical cancer precursor lesions in a retrospective matched cohort. PLoS One, 10(2). https://www.ncbi.nlm.nih.gov/pmc/articles/ PMC4324989/

Nam, K.H., Kwon, J.Y., Kim, Y.-H., \& Park, Y.-W. (2010). Pregnancy outcome after cervical conization: Risk factors for preterm delivery and the efficacy of prophylactic cerclage. Journal of Gynecologic Oncology, 21(4), 225-229. http://doi.org/10.3802/jgo.2010.21.4.225

National Screening Unit. (2008). Guidelines for cervical screening in New Zealand: Incorporating the management of women with abnormal cervical smears. [Guideline]. Wellington: Ministry of Health. Retrieved from https://www.nsu.govt.nz/publications/guidelines-cervical-screening-newzealand

National Screening Unit. (2016). HPV Primary Screening. Retrieved from https://www.nsu.govt.nz/health-professionals/national-cervicalscreening-programme/primary-hpv-screening

Petousis-Harris, H. (2016, February 26). Immunisation Update. Unpublished presentation notes, Warkworth Birthing Centre, New Zealand.

PHARMAC. (2016). Over 100,000 people set to benefit from PHARMAC vaccines decisions. Retrieved from https://www.pharmac. govt.nz/news/media-2016-07-28-vaccines/

Sadler, L., Saftlas, A., Wang, W., Exeter, M., Whittaker, J., \&

McCowan, L. (2004). Treatment for cervical intraepithelial neoplasia and risk of preterm delivery. Journal of the American Medical

Association, 291(17), 2100-2106. http://jama.jamanetwork.com/article. aspx? articleid $=198684$

Sasieni, P., Castanon, A., Landy, R., Kyrgiou, M., Kitchener, H., Poon, L.C.Y., ... Patnick, J. (2016). Risk of preterm birth following surgical treatment for cervical disease: Executive summary of a recent symposium. BJOG: An International Journal of Obstetrics and Gynaecology, 123(9), 1426-1429. http://onlinelibrary.wiley.com/doi/10.1111/1471-

0528.13839/full

Simoens, C., Goffin, F., Simon, P., Barlow, P., Antoine, J., Foidart, J.-M., \& Arbyn, M. (2012). Adverse obstetrical outcomes after treatment of precancerous cervical lesions: A Belgian multicentre study. BJOG: An International Journal of Obstetrics and Gynaecology, 119, 1247-1255. http:// onlinelibrary.wiley.com/doi/10.1111/j.1471-0528.2012.03429.x/full
Statistics New Zealand. (2012). New Zealand women are having their first child at age 30. Retrieved from http://www.stats.govt.nz/browse_ for_stats/population/mythbusters/first-baby-at-30.aspx

Stout, M.J., Frey, H.A., Tuuli, M.G., Cahill, A.G., Odibo, A.O., Roehl, K.A., \& Macones, G.A. (2015). Loop electrosurgical excision procedure and risk of vaginal infections during pregnancy: An observational study. BJOG: An International Journal of Obstetrics and Gynaecology, 122(4), 545551. Retrieved from http://onlinelibrary.wiley.com/doi/10.1111/14710528.13252/full

The New Zealand HPV Project. (2016). The NZ HPV Project.

Retrieved from http://www.hpv.org.nz/the-nz-hpv-project

Wuntakal, R., Castanon, A., Landy, R., \& Sasieni, P. (2015). How many preterm births in England are due to excision of the cervical transformation zone? Nested case control study. BMC Pregnancy and Childbirth, 15, 232. http://bmcpregnancychildbirth.biomedcentral.com/ articles/10.1186/s12884-015-0664-3

\section{Accepted for Publication April 2018}

Hay, R., \& Patterson, J. (2018). Effects of cervical excisional procedures for cervical intraepithelial neoplasia on pregnancy and birth: A literature review. New Zealand College of Midwives Journal, 54, 22-29.

https://doi.org/10.12784/nzcomjn154.2018.3.22-29 